OPEN ACCESS

Edited by:

Noriyuki Koibuchi,

Gunma University Graduate

School of Medicine, Japan

Reviewed by: Giampaolo Papi,

Ausl Modena, Italy

Akira Hishinuma,

Dokkyo Medical University, Japan

Giuseppe Barbesino,

Massachusetts General Hospital, USA

${ }^{*}$ Correspondence:

Johannes W. Dietrich

johannes.dietrich@

ruhr-uni-bochum.de

Specialty section:

This article was submitted to

Thyroid Endocrinology,

a section of the journal

Frontiers in Endocrinology

Received: 31 March 2016

Accepted: 23 May 2016

Published: 09 June 2016

Citation:

Dietrich JW, Landgrafe-Mende $G$,

Wiora E, Chatzitomaris A, Klein HH,

Midgley JEM and Hoermann R (2016)

Calculated Parameters of Thyroid

Homeostasis: Emerging Tools for

Differential Diagnosis and Clinical

Research.

Front. Endocrinol. 7:57.

doi: 10.3389/fendo.2016.00057

\section{Calculated Parameters of Thyroid Homeostasis: Emerging Tools for Differential Diagnosis and Clinical Research}

\author{
Johannes W. Dietrich ${ }^{1,2,3 *}$, Gabi Landgrafe-Mende ${ }^{4}$, Evelin Wiora ${ }^{1}$, \\ Apostolos Chatzitomaris ${ }^{1}$, Harald H. Klein ${ }^{1,2,3}$, John E. M. Midgley ${ }^{5}$ and Rudolf Hoermann ${ }^{6}$ \\ 'Medical Department I, Endocrinology and Diabetology, Bergmannsheil University Hospitals, Ruhr University of Bochum, \\ Bochum, Germany, ${ }^{2}$ Ruhr Center for Rare Diseases (CeSER), Ruhr University of Bochum, Bochum, Germany, ${ }^{3}$ Ruhr Center \\ for Rare Diseases (CeSER), Witten/Herdecke University, Bochum, Germany, ${ }^{4}$ Zentrum für Unfallchirurgie, Orthopädie und \\ Wirbelsäulenchirurgie, HELIOS Klinikum Schwelm, Schwelm, Germany, ${ }^{5}$ North Lakes Clinical, Ilkley, UK, ${ }^{6}$ Department of \\ Nuclear Medicine, Klinikum Luedenscheid, Luedenscheid, Germany
}

Although technical problems of thyroid testing have largely been resolved by modern assay technology, biological variation remains a challenge. This applies to subclinical thyroid disease, non-thyroidal illness syndrome, and those $10 \%$ of hypothyroid patients, who report impaired quality of life, despite normal thyrotropin (TSH) concentrations under levothyroxine (L-T4) replacement. Among multiple explanations for this condition, inadequate treatment dosage and monotherapy with L-T4 in subjects with impaired deiodination have received major attention. Translation to clinical practice is difficult, however, since univariate reference ranges for TSH and thyroid hormones fail to deliver robust decision algorithms for therapeutic interventions in patients with more subtle thyroid dysfunctions. Advances in mathematical and simulative modeling of pituitary-thyroid feedback control have improved our understanding of physiological mechanisms governing the homeostatic behavior. From multiple cybernetic models developed since 1956, four examples have also been translated to applications in medical decision-making and clinical trials. Structure parameters representing fundamental properties of the processing structure include the calculated secretory capacity of the thyroid gland (SPINA-GT), sum activity of peripheral deiodinases (SPINA-GD) and Jostel's TSH index for assessment of thyrotropic pituitary function, supplemented by a recently published algorithm for reconstructing the personal set point of thyroid homeostasis. In addition, a family of integrated models (University of California-Los Angeles platform) provides advanced methods for bioequivalence studies. This perspective article delivers an overview of current clinical research on the basis of mathematical thyroid models. In addition to a summary of large clinical trials, it provides previously unpublished results of validation studies based on simulation and clinical samples.

Keywords: thyroid hormones, homeostasis, SPINA-GT, SPINA-GD, set point, feedback control, thyroid's secretory capacity, sum activity of peripheral deiodinases 


\section{INTRODUCTION}

Thanks to the advent of sensitive assays for TSH and free thyroid hormones, the diagnosis of classical forms of overt hypothyroidism and hyperthyroidism has become a straightforward task (1). Differential diagnosis may still be difficult, however, in some cases with subclinical forms of thyroid failure $(2,3)$, hypothalamic or pituitary dysfunction (4), and in situations of allostatic load, e.g., starvation and non-thyroidal illness syndrome (NTIS) (2, 5, 6). A therapeutic challenge arises from the fact that current standard treatment of hypothyroidism with levothyroxine (L-T4) fails to raise the quality of life (QoL) in patients to a level observed in a normal population (7). Rather, they display symptoms that are compatible with either hypothyroidism and hyperthyroidism, and a fraction of 5-15\% of hypothyroid patients on L-T4 replacement continue to complain about impaired QoL, despite documented biochemical euthyroidism as defined by reference intervals $(7,8)$.

Reasons for low health-related QoL in treated hypothyroidism may include inadequate dosage of substitution therapy with LT4, inadequate treatment modality, systemic sequelae of thyroid autoimmunity, concomitant other autoimmune diseases, and psychological phenomena, especially in form of a nocebo effect (7). Additionally, low reported QoL might ensue from some selection bias, since in most countries thyroid disease is treated by primary care physicians, who may refer "difficult cases" to academic centers, and since most functional thyroid disorders are diagnosed because patients report elements of lower QoL (911). According to the topic of this perspective article, we will focus our subsequent considerations to the former two possible mechanisms.

Inadequate treatment modality refers to potential adverse effects of monotherapy with L-T4, e.g. in a subgroup of hypothyroid patients, who are affected by reduced deiodination due to polymorphic variants with lower enzyme activity $(12,13)$. In this group, additional replacement with L-T3 (and also, possibly, low doses of other classical and non-classical thyroid hormones) may be beneficial. Due to disruption of the thyroid-mediated TSH-T3 shunt $(14,15)$, inefficient conversion of T3 from T4 may also arise in the subgroup of $\mathrm{L}$-T4-treated athyreotic patients $(16,17)$. Narrow individual tolerance to hormone concentrations around the personal set point of thyroid homeostasis may also contribute to considerable variation in the treatment response (18-21). These observations have stimulated a recent debate, whether universal reference ranges for TSH and peripheral thyroid hormones are appropriate (14). Improved diagnostic efficiency has also been observed using multivariate analysis rather than the conventional univariate approaches (22). Based on recent research, we and others have propagated a more comprehensive systems-based approach. This includes the use of homeostatically defined structure parameters (6). Mathematical modeling of pituitary-thyroid feedback control has delivered functional insights beyond the scope of univariate reference ranges $(14,20,23,24)$.

This perspective article gives an overview of current methodology and established and possible future applications of modelingbased diagnostic investigation in vivo.

\section{APPLYING CYBERNETIC MODELS OF THYROID HOMEOSTASIS}

Over the past 60 years, a plethora of mathematical or simulative models of pituitary-thyroid interaction has been published $(6,14)$. Only a small subset, however, has been translated into applications for clinical decision-making or research (beyond the scope of modeling itself). These modeling platforms include the logarithmic standard model of thyroid homeostasis (25), compartment analytical models, which were originally developed at the Biocybernetics Laboratory of the University of California-Los Angeles (subsequently referred to as UCLA platform) (26-31), non-linear models combining Michaelis-Menten kinetics in the feedforward path and non-competitive inhibition in the feedback direction (aka MiMe-NoCoDI models) $(32,33)$, and a so-called "minimal model" that combines Michaelis-Menten kinetics with a logarithmic model of hypothalamic-pituitary function $(20,23$, 24). Thanks to both sufficient empirical foundation and some physiological justification, models derived from these platforms are able to deliver meaningful measures of homeostatic function. Where biochemical knowledge is (or was) insufficient for the development of well-justified models, simple equations, e.g., ratios, have been introduced to deliver an estimate for basic processes of conversion or signal transduction.

\section{APPLICATIONS OF THE UCLA PLATFORM}

This family of models is based on separation of source and sink organ components, implemented as at least three source (organ) and three sink (distribution and elimination) subsystems. Dating back in its origin to 1966 (34-36), it was successively improved to incorporate current findings of basic and clinical research. The most recent implementations of this platform combine Michaelis-Menten kinetics (deiodination) with a threeparameter time-delay model (thyroid), a negative exponential model for feedback inhibition of TSH release, and a non-linear description of plasma protein binding (26-31).

Models of this platform were applied to pharmacokinetic (PK) and pharmacodynamic questions concerning substitution therapy with L-T4 (37). By mathematical modeling and computer simulations, it could be demonstrated that for the majority of hypothyroid patients standard L-T4-only therapy should be sufficient to reach normal triiodothyronine tissue concentrations (28, 29), but that substitution with L-T3 may be beneficial to reduce the withdrawal period before ${ }^{131}$ I remnant ablation in patients with thyroid cancer (26).

Additionally, this platform paved the way for the development of an improved protocol for bioequivalence studies. Thyroid hormones are critical dosage drugs, i.e., small changes in concentration may exert major metabolic effects, and the absorption rate is highly sensitive to multiple influencing factors including meals, coffee, concomitant medication, and gastrointestinal disease (38). Moreover, L-T4 preparations of different brands cannot be considered bioequivalent $(39,40)$. Traditionally, bioequivalence is assessed by PK studies as required by the FDA and other regulatory authorities. Standard protocols are faced with the problem that they ignore the existence of functional feedback in healthy 
volunteers, however. Models based on the UCLA platform delivered an improved baseline correction method that is less prone to this kind of interference $(27,28)$.

\section{MEASURES OF THYROID FUNCTION AND PERIPHERAL HORMONE METABOLISM}

Circulating T4 is actively taken up by cells and biologically activated by enzymatic monodeiodination before exerting (mostly genomic) intracellular effects. The molar T3/T4 ratio may therefore serve as a simple measure of deiodinase activity and conversion efficiency. Numerous studies investigated the T3/T4 ratio in various conditions. They found it to be increased in iodine deficiency (41) and other settings of hyperdeiodination (42-44) possibly accompanied by intrathyroidal hypoiodination and representing an iodine recovery mechanism - and to be decreased in NTIS $(45,46)$, central hypothyroidism ensuing from thyrotropic insufficiency $(47,48)$, congenital thyroid hypoplasia $(47)$, treatment with propranolol (49) and, compared with cases of true hyperthyroidism, in the acute phases of postpartum thyroid dysfunction, subacute, and painless thyroiditis (50-53). It is increased in Graves' disease compared to multinodular toxic goiter and toxic adenoma (51) and decreased in athyreotic patients receiving substitution therapy with L-T4 (54). An observation study found a negative correlation of T3/T4 ratio with age and positive correlation with serum selenium concentration (55). A report on strong negative correlation between FT4 index and T3/T4 ratio remains questionable, since the results were not corrected for spurious correlations (56).

Other measures related to conversion are FT3/reverse T3 (rT3) ratio, an estimate for the proportion of step-up to step-down deiodination, and 3,5-diiodothyronine (3,5-T2)/FT3 ratio. The former parameter is decreased in NTIS (TACITUS), while the latter is increased (57).

However, the simple ratios are conceptually incompatible with known kinetic properties of enzyme-mediated processes, as they wrongly assume linear relationships (6). Reference ranges for ratios are also more difficult to define than for non-fractions (58). These inherent deficiencies made it necessary to derive more robust structure parameters that describe the behavior of transfer elements in homeostatic models $(33,59)$. The novel parameters are based on the MiMe-NoCoDI platform, i.e., Michaelis-Menten functions and PK data to deliver a structure parameter inference approach (SPINA) that provides non-linear estimates of signal transduction (32).

To implement this approach, we estimated the sum activity of peripheral deiodinases $\left(\hat{G}_{\mathrm{D}}\right.$ or SPINA-GD), which reflects the maximum stimulated activity of step-up deiodination. It is calculated with

$$
\hat{G}_{\mathrm{D}}=\frac{\beta_{31}\left(K_{\mathrm{M} 1}+\left[\mathrm{FT}_{4}\right]\right)\left(1+K_{30}[\mathrm{TBG}]\right)\left[\mathrm{FT}_{3}\right]}{\alpha_{31}\left[\mathrm{FT}_{4}\right]}
$$

from equilibrium concentrations of FT4, FT3, and PK constants (Table 1) $(32,60)$. A simpler version employs the concentration of total T3 with

$$
\hat{\mathrm{G}}_{\mathrm{D}}=\frac{\beta_{31}\left(K_{\mathrm{M} 1}+\left[\mathrm{FT}_{4}\right]\right)\left[\mathrm{TT}_{3}\right]}{\alpha_{31}\left[\mathrm{FT}_{4}\right]} .
$$

TABLE 1 | Standard parameters used by the equations for SPINA-GT, SPINA-GD, and Jostel's TSH index $(6,32,60)$

\begin{tabular}{lll}
\hline Symbol & Explanation & Value \\
\hline$\alpha_{T}$ & Dilution factor for thyroxine & $0.1 \mathrm{~L}^{-1}$ \\
$\beta_{T}$ & Clearance exponent for T4 & $1.1 \mathrm{e}-6 \mathrm{~s}^{-1}$ \\
$D_{\mathrm{T}}$ & $\mathrm{EC}_{50}$ for TSH & $2.75 \mathrm{mlU} / \mathrm{L}$ \\
$K_{41}$ & Dissociation constant of T4 at thyroxine-binding globulin & $2 \mathrm{e} 10 \mathrm{~L} / \mathrm{mol}$ \\
$K_{42}$ & Dissociation constant of T4 at transthyretin & $2 \mathrm{e} 8 \mathrm{~L} / \mathrm{mol}$ \\
$\alpha_{31}$ & Dilution factor for triiodothyronine & $0.026 \mathrm{~L}^{-1}$ \\
$\beta_{31}$ & Clearance exponent for T3 & $8 \mathrm{e}-6 \mathrm{~s}^{-1}$ \\
$K_{\mathrm{M} 1}$ & Dissociation constant of type 1 deiodinase & $500 \mathrm{nmol} / \mathrm{L}$ \\
$K_{30}$ & Dissociation constant of T3 at thyroxine-binding globulin & $2 \mathrm{e} 9 \mathrm{~L} / \mathrm{mol}$ \\
{$[T B G]$} & Standard concentration of thyroxine-binding globulin & $300 \mathrm{nmol} / \mathrm{L}$ \\
{$[T B P A]$} & Standard transthyretin concentration & $4.5 \mu \mathrm{mol} / \mathrm{L}$ \\
$\beta$ & Correction coefficient of logarithmic model & 0.1345 \\
\hline
\end{tabular}

Dilution factors are defined as the reciprocal of apparent volume of distribution $\left(V_{D}\right)$.

The reference range for SPINA-GD is typically between 20 and $60 \mathrm{nmol} / \mathrm{s}(57)$, with some dependence on the assays used. Since the dissociation constant of type 1 deiodinase is beyond physiological plasma concentrations of FT4, SPINA-GD is nearly linear in the euthyroid range, so that it has similarities to the T3/T4 ratio. Its non-linear properties are advantageous especially in cases of high FT4 concentrations.

The thyroid's secretory capacity ( $\hat{G}_{\mathrm{T}}$ or SPINA-GT), also referred to as thyroid output or thyroid capacity, provides an estimate for the maximum secretion rate of the thyroid gland under stimulated conditions. It is defined with

$$
\hat{G}_{\mathrm{T}}=\frac{\beta_{\mathrm{T}}\left(D_{\mathrm{T}}+[\mathrm{TSH}]\right)\left(1+K_{41}[\mathrm{TBG}]+K_{42}[\mathrm{TBPA}]\right)\left[\mathrm{FT}_{4}\right]}{\alpha_{\mathrm{T}}[\mathrm{TSH}]}
$$

as a function of equilibrium concentrations of TSH, free T4, and constants or measured values for dissociation, protein binding, distribution, and elimination (Table 1) (32, 60). A simpler version utilizes total $\mathrm{T} 4$ concentration with

$$
\hat{G}_{\mathrm{T}}=\frac{\beta_{\mathrm{T}}\left(D_{\mathrm{T}}+[\mathrm{TSH}]\right)\left[\mathrm{TT}_{4}\right]}{\alpha_{\mathrm{T}}[\mathrm{TSH}]} .
$$

The reference range is usually between 1.4 and $8.7 \mathrm{pmol} / \mathrm{s}$ (57). In silico evaluation with Monte Carlo simulations demonstrates that both SPINA-GT and SPINA-GD can be sufficiently reliably estimated, despite limited accuracy of laboratory assays (Figures 1A,B). In vivo validation confirmed that SPINA-GT is able to clearly differentiate between euthyroidism and functional thyroid disorders of primary origin $(32,61,62)$. However, unlike TSH, it is unaffected by hypothalamic-pituitary dysfunction (Figure 1C; Table S1 in Supplementary Material). This translates to high specificity in thyroid disorders of secondary or tertiary origin. Physiologically, SPINA-GD correlates with the conversion rate of slow tissue pools (Figure 1D), as determined by isotope-based measurements in healthy volunteers (63).

SPINA-GT and SPINA-GD have been validated in numerous clinical trials. In a retrospective comparison with normal controls, SPINA-GT was significantly elevated in patients with toxic adenoma, Graves's disease, and even euthyroid diffuse and nodular goiter and significantly reduced in autoimmune thyroiditis (32). 


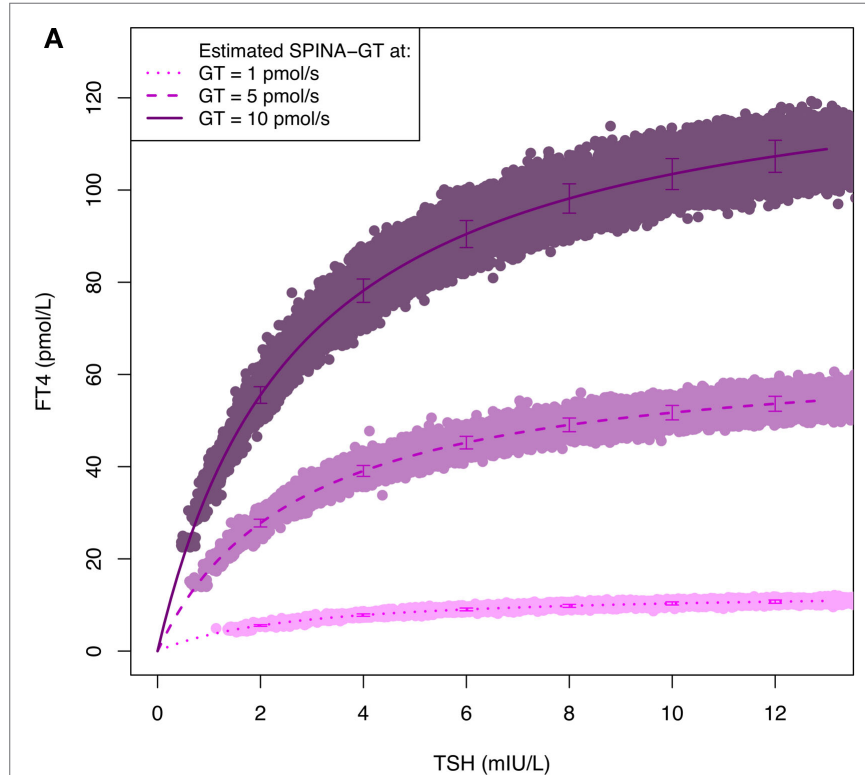

C

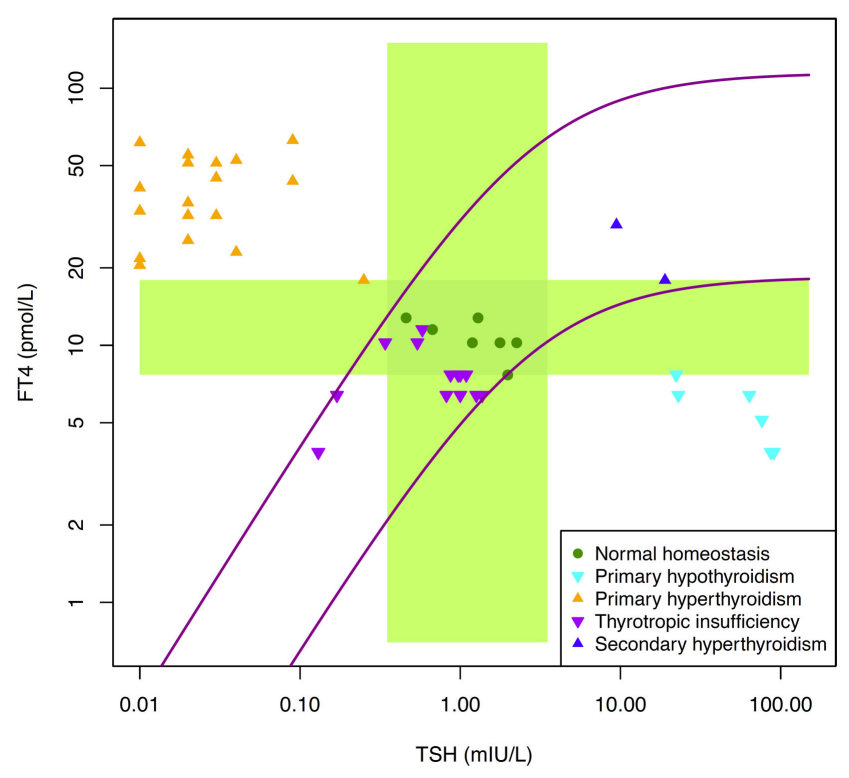

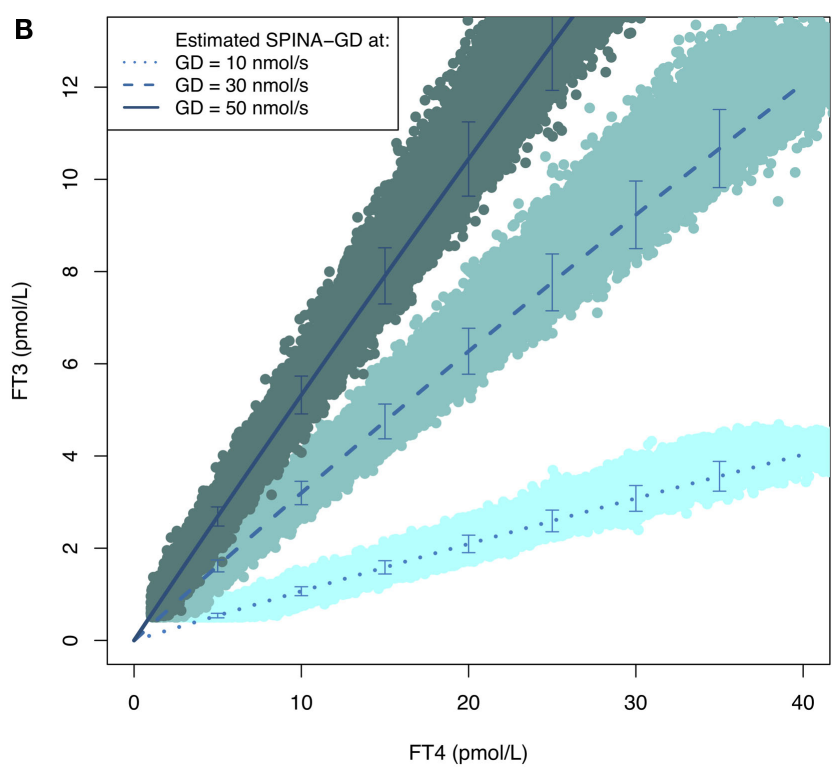

D

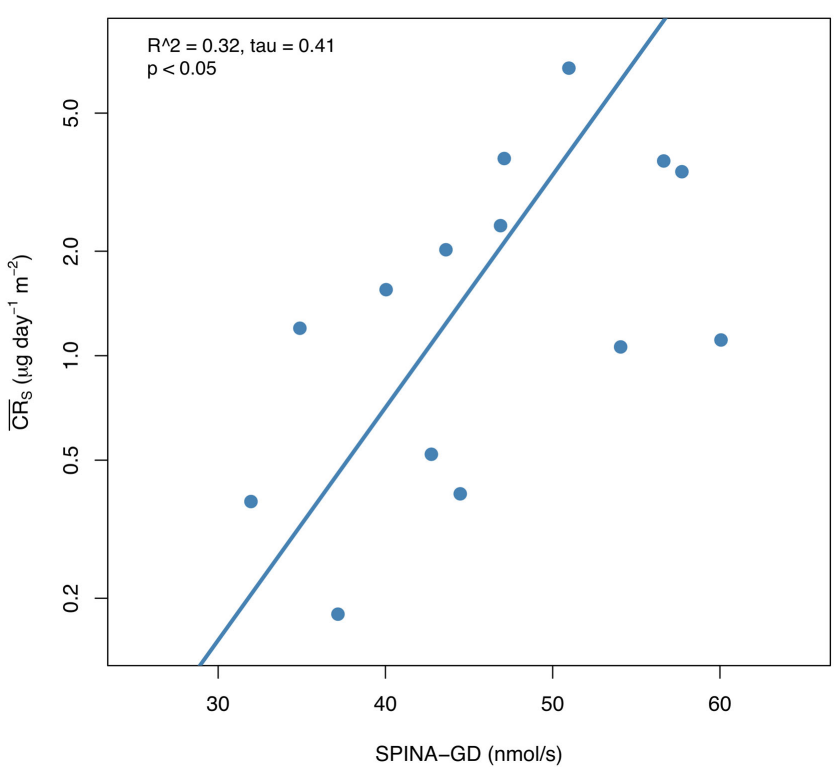

FIGURE 1 | (A,B) Reliability of SPINA-derived parameters is higher than that of measured hormone concentrations. Shown are results of Monte Carlo evaluation of SPINA-GT and SPINA-GD based on simulated imprecise hormone assays. Hormone concentrations were modeled in SimThyr 4.0 (64) with different pre-defined values for GT and GD, respectively. Subsequently, absolute hormone levels were converted to measurements by means of an $\mathrm{S}$ script (see supplementary code for an introductory example) that injected additive and multiplicative noise, in order to get vendor-reported concentration-dependent coefficients of variations (CV) (65, 66). The lines show mean $\pm S D$ of hormone concentrations predicted by structure parameters calculated from simulated noisy measurements. CVs as markers for measurement reliability (67) of SPINA-GT and SPINA-GD are below $10 \%$ in all cases, although CVs of corresponding hormone assays exceed $20 \%$ in low concentrations. (C) SPINA-GT is sensitive for thyroid disorders of primary origin and specific with respect to secondary dysfunction. The plot shows distribution of hormone concentrations in certain primary and secondary thyroid conditions compared to normal percentiles of SPINA-GT. The green crossing rectangles define univariate reference ranges for TSH and FT4, respectively. The purple lines represent FT4 concentrations at the 2 and $97 \%$ percentiles of SPINA-GT. Data from RUBIONERVE (registration number 4905-14 at RUB ethics committee) and NOMOTHETICOS studies (UTN U1111-1122-3273, ClinicalTrials. gov ID NCT01145040). (D) SPINA-GD is an estimate for deiodination. Shown is correlation between SPINA-GD and conversion rate in slow tissue pools. Data from Pilo et al. (63).

In the same study, it had a higher specificity for hyperthyroidism in toxic adenoma than TSH, FT4, or FT3 concentrations (32). A small trial with 20 healthy volunteers revealed the re-test reliability of SPINA-GT to be higher than that of every other parameter $(6$, 32). SPINA-GT was also shown to correlate with thyroid volume (32) and creatinine clearance (68).
Multiple trials demonstrated SPINA-GD to be reduced in NTIS (57, 69-71). One of these trials also reported that SPINA-GD predicts postoperative atrial fibrillation and correlates to age, total atrial conduction time (PA-TDI interval), as well as to concentrations of B-type natriuretic peptide (BNP) and 3,5-T2 (57). Two large trials together covering $>3,500$ participants independently 
revealed SPINA-GD to correlate with TSH concentrations and to be significantly reduced after initiation of substitution therapy with L-T4 $(16,57,72)$. Strong correlation with TSH levels seems to depend on the presence of residual thyroid tissue, since it was preserved in patients with autoimmune thyroiditis, but lacking in a cohort with thyroid cancer after surgery and radioiodine ablation (17). Conversely, FT3 concentrations correlated with LT4 supply in treated cancer patients, while they remained constant over a broad range of SPINA-GT or L-T4 dosage in groups with remaining thyroid tissue. These observations suggest the existence of a thyroid-mediated TSH-T3 shunt, which might represent a compensatory mechanism, mitigating the effects of decreasing thyroid output in onset hypothyroidism $(15,17)$. In patients on L-T4 replacement therapy, SPINA-GD was an independent predictor of L-T4 dose (73).

If confirmed by sufficiently powered clinical trials, possible future applications of the SPINA methodology might include differential diagnosis of primary functional thyroid disorders from dysregulations of secondary or tertiary origin or from thyrotropic adaptation, i.e., transient alterations of TSH concentrations in cases of NTIS $(5,60)$, screening for iodine deficiency, and identification of patients who would benefit from additional substitution therapy with L-T3 $(12,13)$.

\section{ESTIMATED PARAMETERS FOR PITUITARY FUNCTION}

Jostel's TSH index (TSHI) was introduced as a quantitative marker for pituitary thyrotropic function (74). Based on the logarithmic standard model of thyroid homeostasis (25), it is calculated as

$$
\mathrm{TSHI}=\ln ([\mathrm{TSH}])+\beta\left[\mathrm{FT}_{4}\right]
$$

from measured concentrations of TSH and free T4 and a correction coefficient $\beta$ (Table 1). The TSHI has been calibrated in a large sample of $>9,500$ subjects with and without anterior pituitary insufficiency. A $z$-transformed version of the parameter was defined as standardized TSH index (sTSHI) that results with

$$
\text { sTSHI }=\frac{\text { TSHI }-2.7}{0.676}
$$

from mean (2.7) and SD (0.676) of the TSHI in a normal population. Accordingly, its reference range is between -2 and +2 . In the original validation study, gonadotropic insufficiency and lower peak concentrations of growth hormone and cortisol in pituitary stimulation tests were associated with significantly diminished TSHI (74). Recently, it was demonstrated that the TSHI is also reduced in patients with NTIS and thyrotropic adaptation (69).

Another estimate for thyrotropic function, the thyrotroph thyroid hormone resistance index (TTSI, also referred to as thyrotroph thyroxine resistance index or TT4RI), results with

$$
\mathrm{TTSI}=\frac{100[\mathrm{TSH}]\left[\mathrm{FT}_{4}\right]}{l_{u}}
$$

from equilibrium concentrations of TSH and free T4 and the upper limit of the reference interval of FT4 $\left(l_{\mathrm{u}}\right)(75)$. This screening parameter is elevated in cases of resistance to thyroid hormone due to mutations in the THRB gene (RTH Beta, Refetoff syndrome) (75). It may also be a valuable marker for monitoring central response to substitution therapy with triiodothyroacetate (TRIAC) in RTH beta (76). In a large cohort of twin pairs TTSI was strongly influenced by genetic factors (77). A variant of the TTSI (without correction for the upper limit of the reference range) was significantly increased in offspring from long-lived siblings compared to their partners (78). This observation suggests slight resistance to thyroid hormone to be beneficial with respect to longevity.

\section{RECONSTRUCTING THE SET POINT OF THYROID HOMEOSTASIS}

Intra-individual variation of TSH and T4 concentrations is considerably lower than inter-individual variation $(18,21)$. This observation gave rise to the set point theory of thyroid homeostasis, i.e., to the assumption that serum levels of TSH and FT4 are controlled to match a personal, genetically encoded reference. The region around the individual set point is the obvious target for substitution therapy with L-T4. Unfortunately, however, the location of the set point is unknown and inaccessible in the situation of hypothyroidism $(6,19)$. It may also vary in thyroid health, L-T4 treatment (79) and NTIS/TACITUS (2, 5, 80, 81). Recently, an algorithm was published that allows for reconstructing the set point, even in an open-loop situation $(20,23,24)$. The method is based on the minimal model of thyroid-pituitary interaction and on the observation that, in healthy volunteers, the set point is located in the region of the highest curvature of the pituitary response curve. It requires a minimum of two TSH-FT4 pairs, which were obtained with a latency of at least 4 weeks. Then, two parameters, $S$ (multiplier) and $\varphi$ (slope of exponential function), are determined, either algebraically or via regression, to fit the negative exponential function

$$
[\mathrm{TSH}]=S e^{-\varphi\left[\mathrm{FT}_{4}\right]}
$$

to the data. The next step is to find the root of the third derivative of the pituitary function, where the curvature

$$
K=\frac{\varphi^{2} S e^{-\varphi\left[\mathrm{FT}_{4}\right]}}{\left(1+\varphi^{2} S^{2} e^{-2 \varphi\left[\mathrm{FT}_{4}\right]}\right)^{3 / 2}}
$$

is at its maximum. From this, the set point components for FT4 and TSH can be obtained with

$$
\left[\mathrm{FT}_{4}\right]_{\mathrm{SP}}=\frac{\ln (\varphi S \sqrt{2})}{\varphi}
$$

and

$$
[\mathrm{TSH}]_{\mathrm{SP}}=\frac{1}{\varphi \sqrt{2}} .
$$

The algorithm has been validated in a small trial, which revealed in all examined cases a goodness-of-fit between 95 and 99\% (20). It has still not been investigated, however, if a set point-based dose titration regime leads to a better QoL compared 
with the standard strategy on the premise of population-derived reference ranges.

\section{CLOSING REMARKS AND FUTURE PERSPECTIVES}

In this brief overview, we have described several calculated parameters derived from mathematical modeling that have emerged from recent clinical studies, as helpful tools in defining thyroid function. By extending the classical concept of separate measurements of thyroid hormone parameters these markers add new qualitative and quantitative dimensions to the evaluation of thyroid homeostasis.

Multivariate methods should improve diagnostic discrimination, as they account for interrelationships between thyroid parameters and permit determination of personal set points that are more narrowly defined than population-based reference ranges. Measuring conversion efficiency may particularly benefit the subgroup of patients with reduced QoL, despite normal TSH concentrations.

The use of structure parameters offers a more integrated and systemic view and has already delivered important insights into the physiology of pituitary-thyroid feedback control. Clinical applications are still experimental at present, and more trials are required to prove their utility for medical decision-making.

\section{REFERENCES}

1. Bahn RS, Burch HB, Cooper DS, Garber JR, Greenlee MC, Klein I, et al. Hyperthyroidism and other causes of thyrotoxicosis: management guidelines of the American Thyroid Association and American Association of Clinical Endocrinologists. Endocr Pract (2011) 17(3):456-520. doi:10.4158/EP.17.3.456

2. Pantalone KM, Nasr C. Approach to a low TSH level: patience is a virtue. Cleve Clin J Med (2010) 77(11):803-11. doi:10.3949/ccjm.77a.10056

3. Shrier DK, Burman KD. Subclinical hyperthyroidism: controversies in management. Am Fam Physician (2002) 65(3):431-8.

4. Koulouri O, Auldin MA, Agarwal R, Kieffer V, Robertson C, Falconer Smith J, et al. Diagnosis and treatment of hypothyroidism in TSH deficiency compared to primary thyroid disease: pituitary patients are at risk of under-replacement with levothyroxine. Clin Endocrinol (Oxf) (2011) 74(6):744-9. doi:10.1111/j. 1365-2265.2011.03984.x

5. Cho EA, Yoon JH, Kim HK, Kang HC. A case of masked toxic adenoma in a patient with non-thyroidal illness. BMC Endocr Disord (2014) 14:1. doi:10.1186/ 1472-6823-14-1

6. Dietrich JW, Landgrafe G, Fotiadou EH. TSH and thyrotropic agonists: key actors in thyroid homeostasis. J Thyroid Res (2012) 2012:351864. doi:10.1155/ $2012 / 351864$

7. Wiersinga WM. Paradigm shifts in thyroid hormone replacement therapies for hypothyroidism. Nat Rev Endocrinol (2014) 10(3):164-74. doi:10.1038/nrendo. 2013.258

8. Abdalla SM, Bianco AC. Defending plasma T3 is a biological priority. Clin Endocrinol (Oxf) (2014) 81(5):633-41. doi:10.1111/cen.12538

9. Dayan CM, Panicker V. Hypothyroidism and depression. Eur Thyroid J (2013) 2(3):168-79. doi:10.1159/000353777

10. Kong WM, Sheikh MH, Lumb PJ, Naoumova RP, Freedman DB, Crook M, et al. A 6-month randomized trial of thyroxine treatment in women with mild subclinical hypothyroidism. Am J Med (2002) 112(5):348-54. doi:10.1016/ S0002-9343(02)01022-7

11. Quinque EM, Villringer A, Kratzsch J, Karger S. Patient-reported outcomes in adequately treated hypothyroidism - insights from the German versions of ThyDQoL, ThySRQ and ThyTSQ. Health Qual Life Outcomes (2013) 11:68. doi:10.1186/1477-7525-11-68

\section{AUTHOR CONTRIBUTIONS}

JD designed the validation study and developed Monte Carlo simulation software. JD, JM, and $\mathrm{RH}$ drafted the manuscript. GL-M, EW, HK, and AC recruited patients for formal evaluation of structure parameters. All authors read and approved the manuscript.

\section{ACKNOWLEDGMENTS}

The authors wish to thank Christoph Maier, Department of Pain Medicine, Bergmannsheil University Hospitals Bochum, for data contribution via the RUBIONERVE platform.

\section{FUNDING}

Article processing charges were defrayed by the German Research Foundation (Deutsche Forschungsgemeinschaft, DFG) via the programme Scientific Library Services and Information Systems (LIS), and the Open Access Publication Fund of Ruhr-Universität Bochum.

\section{SUPPLEMENTARY MATERIAL}

The Supplementary Material for this article can be found online at http://journal.frontiersin.org/article/10.3389/fendo.2016.00057

12. McAninch EA, Bianco AC. New insights into the variable effectiveness of levothyroxine monotherapy for hypothyroidism. Lancet Diabetes Endocrinol (2015) 3(10):756-8. doi:10.1016/S2213-8587(15)00325-3

13. McAninch EA, Bianco AC. The history and future of treatment of hypothyroidism. Ann Intern Med (2016) 164(1):50-6. doi:10.7326/M15-1799

14. Hoermann R, Midgley JE, Larisch R, Dietrich JW. Homeostatic control of the thyroid-pituitary axis: perspectives for diagnosis and treatment. Front Endocrinol (2015) 6:177. doi:10.3389/fendo.2015.00177

15. Dietrich JW, Midgley JE, Larisch R, Hoermann R. Of rats and men: thyroid homeostasis in rodents and human beings. Lancet Diabetes Endocrinol (2015) 3(12):932-3. doi:10.1016/S2213-8587(15)00421-0

16. Hoermann R, Midgley JE, Giacobino A, Eckl WA, Wahl HG, Dietrich JW, et al. Homeostatic equilibria between free thyroid hormones and pituitary thyrotropin are modulated by various influences including age, body mass index and treatment. Clin Endocrinol (Oxf) (2014) 81(6):907-15. doi:10.1111/cen. 12527

17. Hoermann R, Midgley JE, Larisch R, Dietrich JW. Integration of peripheral and glandular regulation of triiodothyronine production by thyrotropin in untreated and thyroxine-treated subjects. Horm Metab Res (2015) 47(9):674-80. doi:10.1055/s-0034-1398616

18. Andersen S, Pedersen KM, Bruun NH, Laurberg P. Narrow individual variations in serum $\mathrm{T}(4)$ and $\mathrm{T}(3)$ in normal subjects: a clue to the understanding of subclinical thyroid disease. J Clin Endocrinol Metab (2002) 87(3):1068-72. doi:10.1210/jcem.87.3.8165

19. Benhadi N, Fliers E, Visser TJ, Reitsma JB, Wiersinga WM. Pilot study on the assessment of the setpoint of the hypothalamus-pituitary-thyroid axis in healthy volunteers. Eur J Endocrinol (2010) 162(2):323-9. doi:10.1530/EJE-09-0655

20. Goede SL, Leow MK, Smit JW, Dietrich JW. A novel minimal mathematical model of the hypothalamus-pituitary-thyroid axis validated for individualized clinical applications. Math Biosci (2014) 249:1-7. doi:10.1016/j.mbs.2014. 01.001

21. Larisch R, Giacobino A, Eckl W, Wahl HG, Midgley JE, Hoermann R. Reference range for thyrotropin. Post hoc assessment. Nuklearmedizin (2015) 54(3):112-7. doi:10.3413/Nukmed-0671-14-06

22. Hoermann R, Larisch R, Dietrich JW, Midgley JE. Derivation of a multivariate reference range for pituitary thyrotropin and thyroid hormones: diagnostic 
efficiency compared to conventional single-reference method. Eur J Endocrinol (2016) 174(6):735-43. doi:10.1530/EJE-16-0031

23. Goede SL, Leow MK, Smit JW, Klein HH, Dietrich JW. Hypothalamuspituitary-thyroid feedback control: implications of mathematical modeling and consequences for thyrotropin (TSH) and free thyroxine (FT4) reference ranges. Bull Math Biol (2014) 76(6):1270-87. doi:10.1007/s11538-014-9955-5

24. Leow MK, Goede SL, Dietrich JW, Inventors; System and Method for Deriving Parameters for Homeostatic Feedback Control of an Individual. Singapore patent 201208940-5 (2014).

25. Reichlin S, Utiger RD. Regulation of the pituitary-thyroid axis in man: relationship of TSH concentration to concentration of free and total thyroxine in plasma. J Clin Endocrinol Metab (1967) 27(2):251-5. doi:10.1210/jcem-27-2251

26. Ben-Shachar R, Eisenberg M, Huang SA, DiStefano JJ III. Simulation of postthyroidectomy treatment alternatives for triiodothyronine or thyroxine replacement in pediatric thyroid cancer patients. Thyroid (2012) 22(6):595-603. doi:10. 1089/thy.2011.0355

27. Eisenberg M, Distefano JJ. TSH-based protocol, tablet instability, and absorption effects on L-T4 bioequivalence. Thyroid (2009) 19(2):103-10. doi:10.1089/ thy.2008.0148

28. Eisenberg M, Samuels M, DiStefano JJ III. L-T4 bioequivalence and hormone replacement studies via feedback control simulations. Thyroid (2006) 16(12):1279-92. doi:10.1089/thy.2006.16.1279

29. Eisenberg M, Samuels M, DiStefano JJ III. Extensions, validation, and clinical applications of a feedback control system simulator of the hypothalamopituitary-thyroid axis. Thyroid (2008) 18(10):1071-85. doi:10.1089/thy.2007. 0388

30. Eisenberg MC, Santini F, Marsili A, Pinchera A, DiStefano JJ III. TSH regulation dynamics in central and extreme primary hypothyroidism. Thyroid (2010) 20(11):1215-28. doi:10.1089/thy.2009.0349

31. Han SX, Eisenberg M, Larsen PR, DiStefano J III. THYROSIM app for education and research predicts potential health risks of over-the-counter thyroid supplements. Thyroid (2016) 26(4):489-98. doi:10.1089/thy.2015.0373

32. Dietrich JW. In: Schardt F, editor. Der Hypophysen-Schilddrüsen-Regelkreis. Entwicklung und klinische Anwendung eines nichtlinearen Modells. Berlin: Logos-Verlag (2002). $188 \mathrm{p}$.

33. Dietrich JW, Tesche A, Pickardt CR, Mitzdorf U. Thyrotropic feedback control: evidence for an additional ultrashort feedback loop from fractal analysis. Cybern Syst (2004) 35(4):315-31. doi:10.1080/01969720490443354

34. DiStefano JJ. A New Model of the Thyroid Hormone Regulator and a Proposal for Its Experimental Validation. Los Angeles: University of California, Los Angeles (1966).

35. DiStefano JJ III, Stear EB. Neuroendocrine control of thyroid secretion in living systems: a feedback control system model. Bull Math Biophys (1968) 30(1):3-26. doi:10.1007/BF02476936

36. DiStefano JJ III. A model of the normal thyroid hormone glandular secretion mechanism. J Theor Biol (1969) 22(3):412-7. doi:10.1016/0022-5193(69) 90013-7

37. DiStefano JJ III, Mak PH. On model and data requirements for determining the bioavailability of oral therapeutic agents: application to gut absorption of thyroid hormones. Am J Physiol (1979) 236(3):R137-41.

38. Dietrich JW, Brisseau K, Boehm BO. Resorption, Transport und Bioverfügbarkeit von Schilddrüsenhormonen [Absorption, transport and bio-availability of iodothyronines]. Dtsch Med Wochenschr (2008) 133(31-32):1644-8. doi:10. 1055/s-0028- 1082780

39. Hennessey JV. Levothyroxine dosage and the limitations of current bioequivalence standards. Nat Clin Pract Endocrinol Metab (2006) 2(9):474-5. doi:10. 1038/ncpendmet0273

40. Wartofsky L. Levothyroxine: therapeutic use and regulatory issues related to bioequivalence. Expert Opin Pharmacother (2002) 3(6):727-32. doi:10.1517/ 14656566.3.6.727

41. Horn K, Koeppen D, Pickardt CR, Scriba PC. Normalisierung des T3/T4Quotienten im Serum bei Struma-Patienten unter Kaliumjodid: Ein Beispiel der Autoregulation der Schilddrüse. Klin Wochenschr (1975) 53(2):94-5. doi: 10.1007/BF01482716

42. Amino N, Yabu Y, Miki T, Morimoto S, Kumahara Y, Mori H, et al. Serum ratio of triiodothyronine to thyroxine, and thyroxine-binding globulin and calcitonin concentrations in Graves' disease and destruction-induced thyrotoxicosis. J Clin Endocrinol Metab (1981) 53(1):113-6. doi:10.1210/jcem-53-1-113
43. Miyauchi A, Takamura Y, Ito Y, Miya A, Kobayashi K, Matsuzuka F, et al. 3,5,3'Triiodothyronine thyrotoxicosis due to increased conversion of administered levothyroxine in patients with massive metastatic follicular thyroid carcinoma. J Clin Endocrinol Metab (2008) 93(6):2239-42. doi:10.1210/jc.2007-2282

44. Takamatsu J, Sugawara M, Kuma K, Kobayashi A, Matsuzuka F, Mozai $\mathrm{T}$, et al. Ratio of serum triiodothyronine to thyroxine and the prognosis of triiodothyronine-predominant Graves' disease. Ann Intern Med (1984) 100(3):372-5. doi:10.7326/0003-4819-100-3-372

45. Berger MM, Reymond MJ, Shenkin A, Rey F, Wardle C, Cayeux C, et al. Influence of selenium supplements on the post-traumatic alterations of the thyroid axis: a placebo-controlled trial. Intensive Care Med (2001) 27(1):91-100. doi:10.1007/s001340000757

46. Laurberg P. Mechanisms governing the relative proportions of thyroxine and 3,5,3'-triiodothyronine in thyroid secretion. Metabolism (1984) 33(4):379-92. doi:10.1016/0026-0495(84)90203-8

47. Oto Y, Muroya K, Hanakawa J, Asakura Y, Adachi M. The ratio of serum free triiodothyronine to free thyroxine in children: a retrospective database survey of healthy short individuals and patients with severe thyroid hypoplasia or central hypothyroidism. Thyroid Res (2015) 8:10. doi:10.1186/s13044-015-0023-5

48. Sesmilo G, Simo O, Choque L, Casamitjana R, Puig-Domingo M, Halperin I. Serum free triiodothyronine (T3) to free thyroxine (T4) ratio in treated central hypothyroidism compared with primary hypothyroidism and euthyroidism. Endocrinol Nutr (2011) 58(1):9-15. doi:10.1016/j.endonu.2010.09.006

49. Heyma P, Larkings RG, Campbell DG. Effects of propranolol on T3 formation from T4: in vitro and in vivo studies. In: Stockigt JR, Nagataki S, Meldrum E, Barlow JW, Harding PE, editors. Thyroid Research VIII. Canberra: Australian Academy of Science (1980). p. 420-3.

50. Amino N, Yabu Y, Kuro R, Miyai K, Kumahara Y. T3/T4 ratio in thyroid disease. Lancet (1979) 1(8107):107. doi:10.1016/S0140-6736(79)90100-4

51. Carle A, Knudsen N, Pedersen IB, Perrild H, Ovesen L, Rasmussen LB, et al. Determinants of serum T4 and T3 at the time of diagnosis in nosological types of thyrotoxicosis: a population-based study. Eur J Endocrinol (2013) 169(5):537-45. doi:10.1530/EJE-13-0533

52. Mortoglou A, Candiloros H. The serum triiodothyronine to thyroxine (T3/T4) ratio in various thyroid disorders and after levothyroxine replacement therapy. Hormones (2004) 3(2):120-6. doi:10.14310/horm.2002.11120

53. Yoshimura Noh J, Momotani N, Fukada S, Ito K, Miyauchi A, Amino N. Ratio of serum free triiodothyronine to free thyroxine in Graves' hyperthyroidism and thyrotoxicosis caused by painless thyroiditis. Endocr J (2005) 52(5):537-42. doi:10.1507/endocr. 52.537

54. Gullo D, Latina A, Frasca F, Le Moli R, Pellegriti G, Vigneri R. Levothyroxine monotherapy cannot guarantee euthyroidism in all athyreotic patients. PLoS One (2011) 6(8):e22552. doi:10.1371/journal.pone.0022552

55. Olivieri O, Girelli D, Azzini M, Stanzial AM, Russo C, Ferroni M, et al. Low selenium status in the elderly influences thyroid hormones. Clin Sci (Lond) (1995) 89(6):637-42. doi:10.1042/cs0890637

56. Wilkin TJ, Isles TE. The behavior of the triiodothyronine/thyroxine (T3/T4) ratio in normal individuals, and its implications for the regulation of euthyroidism. J Endocrinol Invest (1984) 7(4):319-22. doi:10.1007/BF03351009

57. Dietrich JW, Müller P, Schiedat F, Schlömicher M, Strauch J, Chatzitomaris A, et al. Nonthyroidal illness syndrome in cardiac illness involves elevated concentrations of 3,5-diiodothyronine and correlates with atrial remodeling. Eur Thyroid J (2015) 4(2):129-37. doi:10.1159/000381543

58. Franz VH. Ratios: A Short Guide to Confidence Limits and Proper Use. (2007). ArXiv: 0710.2024vl. Available at: http://arxiv.org/abs/0710.2024

59. Dietrich JW, Mitzdorf U, Weitkunat R, Pickardt CR. The pituitary-thyroid feedback control: stability and oscillations in a new nonlinear model. J Endocrinol Invest (1997) 20:100.

60. Dietrich JW, Stachon A, Antic B, Klein HH, Hering S. The AQUA-FONTIS study: protocol of a multidisciplinary, cross-sectional and prospective longitudinal study for developing standardized diagnostics and classification of nonthyroidal illness syndrome. BMC Endocr Disord (2008) 8:13. doi:10.1186/14726823-8-13

61. Dietrich JW, Fischer MR, Jauch J, Pantke E, Gärtner R, Pickardt CR. SPINATHYR: a novel systems theoretic approach to determine the secretion capacity of the thyroid gland. Eur J Intern Med (1999) 10(Suppl 1):S34.

62. Wang X, Liu H, Chen J, Huang Y, Li L, Rampersad S, et al. Metabolic characteristics in obese patients complicated by mild thyroid hormone deficiency. Horm Metab Res (2016) 48(5):331-7. doi:10.1055/s-0042-105150 
63. Pilo A, Iervasi G, Vitek F, Ferdeghini M, Cazzuola F, Bianchi R. Thyroidal and peripheral production of 3,5,3'-triiodothyronine in humans by multicompartmental analysis. Am J Physiol (1990) 258(4 Pt 1):E715-26.

64. Dietrich JW. SimThyr. 4.0 ed. Fairfax, VA: SourceForge (1994-2016). RRID:SCR_014351.

65. Clerico A, Ripoli A, Zucchelli GC, Plebani M. Harmonization protocols for thyroid stimulating hormone (TSH) immunoassays: different approaches based on the consensus mean value. Clin Chem Lab Med (2015) 53(3):377-82. doi:10. 1515/cclm-2014-0586

66. Spencer CA, Takeuchi M, Kazarosyan M. Current status and performance goals for serum thyrotropin (TSH) assays. Clin Chem (1996) 42(1):140-5.

67. Shechtman O. The coefficient of variation as an index of measurement reliability. In: Doi SAR, Williams GM, editors. Methods of Clinical Epidemiology. Springer Series on Epidemiology and Public Health. Berlin; Heidelberg: Springer (2013). p. 39-49.

68. Rosolowska-Huszcz D, Kozlowska L, Rydzewski A. Influence of low protein diet on nonthyroidal illness syndrome in chronic renal failure. Endocrine (2005) 27(3):283-8. doi:10.1385/ENDO:27:3:283

69. Fan S, Ni X, Wang J, Zhang Y, Tao S, Chen M, et al. Low triiodothyronine syndrome in patients with radiation enteritis: risk factors and clinical outcomes an observational study. Medicine (Baltimore) (2016) 95(6):e2640. doi:10.1097/ MD.0000000000002640

70. Han G, Ren J, Liu S, Gu G, Ren H, Yan D, et al. Nonthyroidal illness syndrome in enterocutaneous fistulas. Am J Surg (2013) 206(3):386-92. doi:10.1016/j. amjsurg.2012.12.011

71. Liu S, Ren J, Zhao Y, Han G, Hong Z, Yan D, et al. Nonthyroidal illness syndrome: is it far away from Crohn's disease? J Clin Gastroenterol (2012) 47(2):153-9. doi:10.1097/MCG.0b013e318254ea8a

72. Hoermann R, Midgley JE, Larisch R, Dietrich JW. Is pituitary TSH an adequate measure of thyroid hormone-controlled homoeostasis during thyroxine treatment? Eur J Endocrinol (2013) 168(2):271-80. doi:10.1530/EJE-12-0819

73. Midgley JE, Larisch R, Dietrich JW, Hoermann R. Variation in the biochemical response to l-thyroxine therapy and relationship with peripheral thyroid hormone conversion efficiency. Endocr Connect (2015) 4(4):196-205. doi:10.1530/ EC-150056

74. Jostel A, Ryder WD, Shalet SM. The use of thyroid function tests in the diagnosis of hypopituitarism: definition and evaluation of the TSH Index. Clin Endocrinol (Oxf) (2009) 71(4):529-34. doi:10.1111/j.1365-2265.2009.03534.x

75. Pohlenz J, Weiss RE, Macchia PE, Pannain S, Lau IT, Ho H, et al. Five new families with resistance to thyroid hormone not caused by mutations in the thyroid hormone receptor beta gene. J Clin Endocrinol Metab (1999) 84(11):3919-28. doi:10.1210/jc.84.11.3919

76. Chatzitomaris A, Köditz R, Hoeppner W, Peters S, Klein HH, Dietrich JW. A novel de novo mutation in the thyroid hormone receptor-beta gene. Exp Clin Endocrinol Diabetes (2015) 123:P01_03. doi:10.1055/s-00351547617

77. Panicker V, Wilson SG, Spector TD, Brown SJ, Falchi M, Richards JB, et al. Heritability of serum TSH, free T4 and free T3 concentrations: a study of a large UK twin cohort. Clin Endocrinol (Oxf) (2008) 68(4):652-9. doi:10.1111/j.13652265.2007.03079.x

78. Jansen SW, Akintola AA, Roelfsema F, van der Spoel E, Cobbaert CM, Ballieux $\mathrm{BE}$, et al. Human longevity is characterised by high thyroid stimulating hormone secretion without altered energy metabolism. Sci Rep (2015) 5:11525. doi:10. 1038/srep 11525

79. Midgley JE, Hoermann R, Larisch R, Dietrich JW. Physiological states and functional relation between thyrotropin and free thyroxine in thyroid health and disease: in vivo and in silico data suggest a hierarchical model. J Clin Pathol (2013) 66(4):335-42. doi:10.1136/jclinpath-2012-201213

80. Dietrich JW. [Thyroid storm]. Med Klin Intensivmed Notfmed (2012) 107(6):448-53. doi:10.1007/s00063-012-0113-2

81. Rohrer S, Dietrich JW. Das Refeeding-Syndrom - Eine Literaturübersicht [Refeeding syndrome: a review of the literature]. Z Gastroenterol (2014) 52(6):593-600. doi:10.1055/s-0034-1366430

Conflict of Interest Statement: JD received funding and personal fees from SanofiHenning, Hexal AG, and Pfizer and is the co-owner of the intellectual property rights for the patent "System and Method for Deriving Parameters for Homeostatic Feedback Control of an Individual" (Singapore Institute for Clinical Sciences, Biomedical Sciences Institutes, Application Number 201208940-5, WIPO number $\mathrm{WO} / 2014 / 088516)$. All other authors declare that there is no conflict of interest that could be perceived as prejudicing the impartiality of the research reported.

Copyright (C) 2016 Dietrich, Landgrafe-Mende, Wiora, Chatzitomaris, Klein, Midgley and Hoermann. This is an open-access article distributed under the terms of the Creative Commons Attribution License (CC BY). The use, distribution or reproduction in other forums is permitted, provided the original author(s) or licensor are credited and that the original publication in this journal is cited, in accordance with accepted academic practice. No use, distribution or reproduction is permitted which does not comply with these terms. 